\title{
National Atlas of the United States ${ }^{\circledR}$ Maps
}

\section{Maps Available}

The "National Atlas of the United States of America ${ }^{\circledR}$ ", published by the U.S. Geological Survey (USGS) in 1970, is out of print, but many of its maps can be purchased separately. Maps that span facing pages in the atlas are printed on one sheet. Maps dated after 1970 and before 1997 are either revisions of original atlas maps or new maps published in the original atlas format.

The USGS and its partners in government and industry began work on a new "National Atlas" in 1997. Though most new atlas products are designed for the World Wide Web, we are continuing our tradition of printing high-quality maps of America. In 1998 , the first completely redesigned maps of the "National Atlas of the United States ${ }^{\circledR}$ " were published.

Refer to the "USGS Maps Price List" for the most recent prices of all USGS maps and the "USGS Maps, Books, and Other Published Products Order Form" for ordering instructions.

For more information or ordering assistance, call 1-888-ASK-USGS.

\section{Thematic Maps}

The standard thematic map scale is $1: 7,500,000$ but may vary from $1: 17,000,000$ to $1: 34,000,000$ when there is more than one map to a sheet. Unless otherwise noted, the sheet size is 19 by 28 inches and includes data for the conterminous United States, Alaska, and Hawaii.

Forest Cover Types (2000) -- Shows the extent of nearly two dozen major forest cover types derived from satellite images. Alaska, Hawaii, Puerto Rico, and the U.S. Virgin Islands are shown at the same scale, $1: 7,500,000$. The sheet size is 32 by 28 inches. TUS0420

Shaded Relief (1999) -- A stunning portrayal of continental terrain, this map combines an easily interpreted image of America's landscape with 23 elevation gradients. Scale $1: 10,000,000$. Sheet size is 39 by 43.5 inches. TUS5682

Hydrologic Units (1998) -- Depicts a hydrologic system that divides and subdivides the United States into successively smaller river basin units. Units outlined on this map represent natural and manmade streamdrainage areas (watersheds). Scale $1: 3,500,000$. Sheet size is 58 by 40 inches. TUS5681

Principal Aquifers of the United States (1998) -- Shows the distribution of principal aquifers that supply ground water to the United States, Puerto Rico, and the U.S. Virgin Islands. Scale 1:5,000,000. Sheet size is 41 by 29.5 inches. TUS5680

Federal and Indian Lands (1998) -- Shows principal U.S. lands administered or held in trust by Federal agencies and Indian Lands. Areas of less than 23,000 acres are generally not shown. Sheet size is 19 by 29 inches. TUS1445

U.S. Satellite View (1990) -- Consists of a mosaic of 16 advanced very high resolution radiometer images taken from 1984 to 1986 and covering the conterminous United States, with explanatory captions on a mosaic duplication on the reverse side. US5659

Presidential Election of 1988 (1989) -Displays results of the 1988 election by county, plus United States totals for popular electoral votes. US5650

Surface Water (1988) -- Five maps and a series of graphs illustrate annual and monthly runoff, runoff of large rivers, and surface water availability. Supplement to Surface Water (1965). US5663

National Wilderness Preservation System (1987) -- Displays location of congressionally designated wilderness areas with administering agencies indicated. All maps are at $1: 5,000,000$ scale. Sheet size is 42 by 28 inches. US5578
Counties (1987) -- Names and boundaries of counties and county equivalents are shown with State names and boundaries. US5626

Highways (1987) -- Shows the complete interstate system with route markers and other selected major highways. US5630

Territorial Growth (1986) -- Thirteen maps show the territory of the United States at various years between 1775 and 1920. One map shows the United States and its outlying areas as of March 1, 1986. US0664

Potential Natural Vegetation (1985) -Depicts distribution of eastern and western forest and western shrub and grassland types. Text on the reverse side. US0477

Soils (1985) -- Shows principal kinds of soils (orders, suborders, and great groups), with expanded definitions of classification on the reverse side. US0474

Coastal Erosion and Accretion (1985) -Indicates annual shoreline change by bands of color adjacent to the coast. Text and illustrations on the reverse side. US5644

Coastal Hazards (1985) -- Illustrates eight coastal and onshore hazard factors and the resulting overall hazard assessment by bands of color adjacent to the coast. Text and illustrations on the reverse side. US5649

Engineering Aspects of Karst (1984) -Shows distribution of karst features and other features similar to karst. Text on the reverse side. US5572

Principal Federal Lands Where Exploration and Development of Mineral Resources are Restricted (1981) -- Displays areas of 5,000 acres or more where mineral development is formally prohibited, or severely, moderately, or slightly restricted. Text and maps of Alaska and Hawaii on the reverse side. US0421

Surficial Geology (1979) -- Shows distribution of transported, untransported, and miscellaneous deposits for the conterminous 
United States, with text on the reverse side. US00708

Population Distribution, Urban and Rural (1970) -- Cities of more than 50,000 are shown by proportional circles: smaller cities and rural areas are shown by dots. US0564

Population (1970) -- Four maps show population trends 1940-70, population density in 1970, percentage of change in population during 1960-70, and percentage of urban areas in 1970. US0665

United States Shaded Relief (1969) -Illustrates the landforms of the conterminous United States, with insets of Alaska and Hawaii. US0460

Alaska Shaded Relief (1969) -- Includes text on landforms, geology, and other features of the United States. US0461

Annual Sunshine, Evaporation, and Solar Radiation (1969) -- Three maps display mean annual sunshine, annual pan evaporation, and May-October evaporation. Five maps show annual solar radiation and mean solar radiation for January, April, July, and October. US0565

Physiography and Physiographic Divisions (1968) -- Consists of four maps of the conterminous United States showing physiographic regions and provinces, physical divisions, and a physiographic diagram, and one map with insets of Alaska and Hawaii showing topographic relief. US0462

Land-Surface Form (1968) -- Map of Alaska has text on classes of United States landsurface forms and map showing physical subdivisions. US0465

Tectonic Features (1968) -- Alaska map has text on U.S. tectonic maps and features. US0470

Tectonic Features (1967) -- Shows tectonic features of the conterminous United States, with an inset of Hawaii. US0467

Early Indian Tribes, Culture Areas, and Linguistic Stocks (1967) -- Shows distribution of early Indian tribes, with brief text on the reverse side. US5158

Geology (1966) -- Illustrates distribution of sedimentary, volcanic, and intrusive rock types. US0471

Monthly Sunshine (1965) -- One map displays theoretical maximum and mean actual hours of yearly sunshine for selected locations. Twelve maps show mean actual hours of sunshine by month. US0478

Monthly Average Temperature (1965) -One map of yearly mean daily high, mean, and mean daily low temperature for selected locations. Twelve maps of mean temperature by month. US0661

Monthly Minimum Temperature (1965) -One map displays yearly mean, mean daily low, and record daily low temperature for selected locations. Twelve maps show mean minimum temperature by month. US0662

Monthly Maximum Temperature (1965) -One map displays yearly mean, mean daily high, and record daily high temperature for selected locations. Twelve maps show mean maximum temperature by month. US5577

Surface Water (1965) -- Four maps of the conterminous United States show normal monthly runoff, maximum and minimum annual runoff, and coefficient of variation, with text. US0663

Classes of Land-Surface Form (1964) --

Shows land-surface forms of the conterminous United States, with an inset of Hawaii. US0466

Population Distribution, Urban and Rural (1960) -- Cities of more than 50,000 are shown by proportional circles; smaller cities and rural areas are shown by dots. US0444

\section{Presidential Elections (1789-1968 and} 1972-84) -- Shows results of the 1789-1968 elections by State, and of the 1972-84 elections by county, plus United States totals. US5627

\section{Reference Maps}

The 1:2,000,000-scale (approximately 1 inch to 31.5 miles) sectional maps from 1970 portray international and State boundaries and names, railroads, and locations and names of cities in black; larger cities and boundary highlights in yellow; county boundaries and names in gray; airfields, highways, and roads in red; water features in blue; and major physical features in brown. National parks, monuments, forests, wildlife refuges, and Indian reservations are differentiated by tints. State capitals and county seats are also identified. Contours are not shown. Maps are printed on one side of the 19 - by 28 -inch sheet.
These maps have been designed so that each State is shown in its entirety on at least one sheet, with the exceptions of Alaska, California, Montana, and Texas. The complete set of sheets for the conterminous United States can be trimmed of overlap areas and mosaicked to form an approximately 92 by 57 -inch composite map.

U.S. General Reference (2001) -- The conterminous United States, Hawaii, Puerto Rico, and the U.S. Virgin Islands are shown at 1:5,000,000 scale, and Alaska is shown at $1: 15,000,000$ scale. Names of populated places and railroads are shown in black, State boundaries and names in gray, highways in red, ferries and water features in blue, and names of physical features and elevations in brown. The sheet size is 42 by 30 inches. TUS0438

Central Plains States (1973) -- Nebraska, Colorado, Kansas. US0441

Southern Plains States (1973) -- Oklahoma, northern Texas. US0442

Southern Texas (1973) US0443

Arizona and New Mexico (1973) US0447

Southern California (1973) US0449

Northwestern States (1973) -- Idaho, western Montana, Oregon, Washington. US0451

\section{Central Alaska (1973) US0454}

Northern Alaska (1973) US0456

Southwestern Alaska (1973) US0457

Aleutian Islands (1973) US0458

Northeastern States (1972) -- Maine, New Hampshire, Vermont, New York, Massachusetts, Connecticut, Rhode Island. US0464

Middle Atlantic States (1972) -Pennsylvania, New Jersey, Delaware, Maryland, Virginia, West Virginia, Ohio. US0473

Southeastern States (1972) -- North Carolina, South Carolina, Georgia. US0423

Florida (1972) US0426

Southern Mississippi Valley States (1972) -Alabama, Mississippi, Louisiana, Arkansas, Tennessee. US0429 
Central Mississippi Valley States (1972) -Indiana, Illinois, Iowa, Missouri, Kentucky. US0432

Northern Great Lakes States (1972) --

Michigan, Wisconsin, Minnesota. US0435

Northern Plains States (1972) -- North Dakota, South Dakota, Eastern Montana, Wyoming. US0440

Central Pacific States (1972) -- Nevada, northern California, Utah. US0450

Hawaiian Islands (1972) US0452

Southeastern Alaska (1972) US0453

\section{Information}

The "National Atlas" now offers online, interactive mapping services at the following location on the World Wide Web:

www.nationalatlas.gov/.

National Atlas Maps can also be searched and ordered using Earth Explorer at earthexplorer.usgs.gov.

For information on these and other USGS products and services, call 1-888-ASK-USGS, use the Ask.USGS

fax service, which is available 24 hours a day at 703-648-4888, or visit the general interest publications Web site on mapping, geography, and related topics at mac.usgs.gov/mac/isb/pubs/ pubslists/.

For additional information, visit the ask.usgs.gov Web site or the USGS home page at www.usgs.gov.

“National Atlas of the United States ${ }^{\circledR}$ " and "The National Atlas of the United States of America ${ }^{\circledR ”}$ are trademarks of the U.S.

Department of the Interior. 